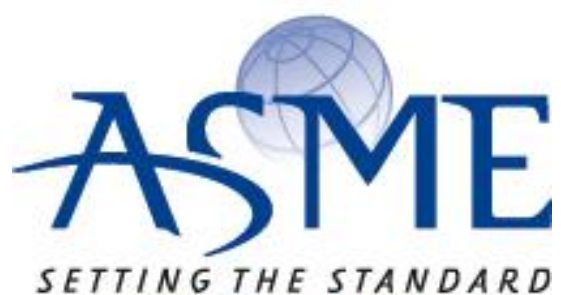

SETTING THE STANDARD

\section{American Society of Mechanical Engineers}

ASME Accepted Manuscript Repository

Institutional Repository Cover Sheet

Jan

Zanger

First

Last

ASME Paper Title: Experimental Investigation of Cycle Properties, Noise and Air Pollutant Emissions of an APS3200

Auxiliary Power Unit

Authors: $\quad$ T. Siebel, J. Zanger, A. Huber, M. Aigner, K. Knobloch, F. Bake

ASME Journal Title: J. Eng. Gas Turbines Power

Date of Publication (VOR* Online) 13. Feb. 2018

Volume/Issue $140(6)$

ASME Digital Collection URL: http://gasturbinespower.asmedigitalcollection.asme.org/article.aspx?articleid=26575

DOI:

*VOR (version of record) 


\title{
Experimental Investigation of Cycle Properties, Noise and Air Pollutant Emissions of an APS3200 Auxiliary Power Unit
}

\author{
Teresa Siebel, Jan Zanger, Andreas Huber, Manfred Aigner \\ Institute of Combustion Technology \\ German Aerospace Center (DLR) \\ Stuttgart, Germany 70569 \\ Email: teresa.siebel@dlr.de \\ Karsten Knobloch, Friedrich Bake \\ Institute of Propulsion Technology \\ German Aerospace Center (DLR) \\ Berlin, Germany 10623
}

\begin{abstract}
Auxiliary power unit (APU) operators face increasingly stricter airport requirements concerning exhaust gas and noise emission levels. To simultaneously reduce exhaust gas and noise emissions and to satisfy the increasing demand of electric power on board, optimization of the current technology is necessary. Prior to any possible demonstration of optimization potential, detailed data of thermodynamic properties and emissions have to be determined. Therefore, the investigations presented in this paper were conducted at a full-scale APU of an operational aircraft. A Pratt \& Whitney APS3200, commonly installed in the Airbus A320 aircraft family, was used for measurements of the reference data. In order to describe the APS3200, the full spectrum of feasible power load and bleed air mass flow combinations were adjusted during the study. Their effect on different thermodynamic and performance properties, such as exhaust gas temperature, pressure as well as electric and overall efficiency is described. Furthermore, the mass flows of the inlet air, exhaust gas and fuel input were determined. Additionally, the work reports the exhaust gas emissions regarding the species $\mathrm{CO}_{2}, \mathrm{CO}$ and $\mathrm{NOx}$ as a function of load point. Moreover the acoustic noise emissions are presented and discussed. With the provided data the paper serves as a database for validating numerical simulations and provides a baseline for current APU technology. Keywords: auxiliary power unit, operating range, cycle properties, NOx, CO, acoustic spectra
\end{abstract}

\author{
Nomenclature \\ APU Auxiliary power unit \\ AFR Air fuel ratio \\ BCV Bleed control valve \\ CC Combustion chamber \\ FFT Fast Fourier transform \\ G Generator \\ ICAO Intern. Civil Aviation Organization \\ SPL Sound pressure level \\ UHC Unburned hydrocarbons \\ MEA More electric aircraft \\ MGT Micro gas turbines \\ VIGV Variable inlet guide vane \\ $T$ Temperature $\left({ }^{\circ} \mathrm{C}\right)$ \\ $c_{p} \quad$ Heat capacity at $p=$ const. $(\mathrm{J} / \mathrm{kgK})$ \\ $H$ Lower heating value $(\mathrm{kJ} / \mathrm{kg})$
}

*Address all correspondence to this author.

GTP-17-1390 / Siebel

C2017 by ASME. This manuscript version is made available under the CC-BY 4.0 license

http://creativecommons.org/licenses/by/4.0/

The original publication is available at http://dx.doi.org/10.1115/1.4038159 


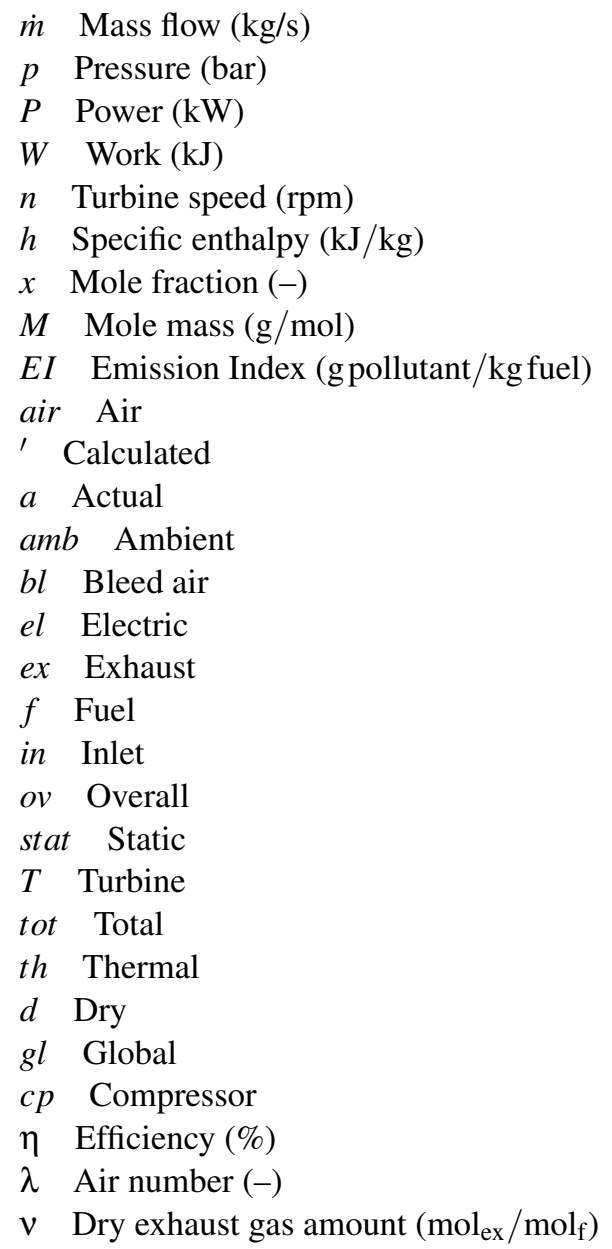

\section{INTRODUCTION}

Many airports experience a constantly rise in aircraft operations and a simultaneous increase in public concern about pollutant and noise emissions. In order to reduce the impact on surrounding areas, airports are implementing air quality and noise mitigation plans. Different relevant emission factors, such as traffic to and from the airport and energy consumption of infrastructure and aircraft - in flight and on ground - are determined. On ground auxiliary power units (APU) are seen as one of the major sources of pollutant and noise emissions [1]. Therefore, many airports in urban areas are restricting their usage. APUs are installed to supply vital loads in case of main engine or generator failure and to provide compressed air and electric power on ground for air condition, power supply and main engine start up. In contrast to the airport specification of reduced APU-usage, aircrafts require increasing amounts of electrical power. A trend towards a More Electric Aircraft (MEA) with decentralized electric-mechanical actuators and electric operated air conditioning can be seen. The concept is already partly implemented in the new developed Airbus A380 and Boeing 787. Additionally, the objective for higher passenger comfort with improved air conditioning and consumer electronics will further increase the demand of electricity. To meet these contradictory demands, optimization of todays APUs is necessary.

Prior to any possible demonstration of optimization potential, knowledge of state of the art APUs, their thermodynamic properties and pollutant and noise emission characteristics are of great importance. So far, there are very few publications regarding the APU cycle, none of which supply enough data for validating numerical simulations. Some basic information is published by the manufacturers, such as rotational speed, weight and maximum bleed air output, however no detailed cycle relevant data [2], [3]. As airports attempt to mitigate pollutants more research has been conducted on the topic of exhaust gas emissions. Kinsey et al. [4] determined the exhaust gas emissions of a Honeywell GTCP85-98CK APU using both JP-8 and a coal-derived Fischer Tropsch fuel (FT-2). However, both fuels are not commonly used in civil aviation. Measurements of exhaust gas emissions were conducted using a Rolls Royce Artouste Mk113 APU (aircraft retired 1993) by Crayford et al. [5]. They present typical indices for gaseous emissions as well as smoke and particle emission data for idle and full power conditions. In a recent publication by Lobo et al. [6], the exhaust gas emissions of 16 different blends of alternative fuels compared with a conventional Jet A-1 are shown. The systematic evaluation of emissions was conducted with a Honeywell GTCP85 APU at three different operating conditions. Although the before mentioned papers state that the APU contributes significantly to airport emissions, there are presently no ICAO standards related to aircraft APU systems [7]. 
In terms of noise emissions and signature, the APU is, due to the absence of a high-velocity jet, somewhat different from jet propulsion aero-engines. Only a few investigations dedicated to APU noise have been reported in the literature, sometimes also in order to compare the APU system with the core of an aero-engine. Tam ( [8] and [9]) investigated isolated Honeywell APUs of different size, with respect to the frequency content, angular directivity and also with respect to a distinction between direct (originating in the combustion process itself) and indirect (being generated when entropy or vorticity fluctuations being accelerated or decelerated) combustion noise. Latter distinction was made assuming a common shape of combustion noise spectra, which was claimed to be universal. Pott-Polenske [10] acquired spectra for several APUs during their operation in different aircraft types - with and without air condition bleed air venting. Except for the Airbus A340 (which has an asymmetric installation), all measurements were found to be symmetric with respect to the axis of mean flow, with corrected values for the SPL between 100 and $120 \mathrm{~dB}(\mathrm{~A})$. The maximum SPL usually occured at a measured $30^{\circ}$ angle from the flow axis. The engagement of the cabin air condition showed ambiguous changes to the noise emissions depending on aircraft type and most likely on the way and place of bleed air dump. The maximum of dominating broadband noise occured in the range of $500-2000 \mathrm{~Hz}$, where all spectra was strongly damped above $10 \mathrm{kHz}$. In another investigation, measurements on a stand-alone APU unit were made focusing on the performance of the muffler face sheet material [11].

The present paper describes an experimental investigation of the thermodynamic properties and exhaust gas and noise emissions of a full-scale Hamilton Sundstrand (now Pratt \& Whitney) APS3200, as installed on commercial airplanes like the Airbus A320. The APS3200 is a gas turbine with a load and power section. Both compressors and the turbine are on one shaft, which drives the gear box and thus the electric generator. The power section consists of a centrifugal impeller with one stage and an axial flow turbine with two stages. The integrated combustion chamber is designed as a reverse flow, annular chamber. Bleed air is obtained from the load compressor section, which is a centrifugal impeller with variable inlet guide vanes (VIGV). The APS3200 has a height of $76 \mathrm{~cm}$, a width of $85 \mathrm{~cm}$ and a length of $125 \mathrm{~cm}$ [2]. For the basic dry weight $140 \mathrm{~kg}$ are given. Starting and operating of the APS3200 is possible up to 12500 meter above sea level.

In contrast to the aforementioned studies, commercially available Jet A-1 was used to characterize the state-of-the-art APU. This work provides a data base for system simulation with thermodynamic properties and exhaust gas and noise emissions of a full scale APU.

\section{EXPERIMENTAL SETUP}

A Lufthansa Technik AG operated test rig for the final operation test of overhauled APUs was used in the presented study. Additional test equipment, such as temperature and pressure sensors, a flue gas analyzer and microphones were installed. The experimental setup is shown in Fig. 1.

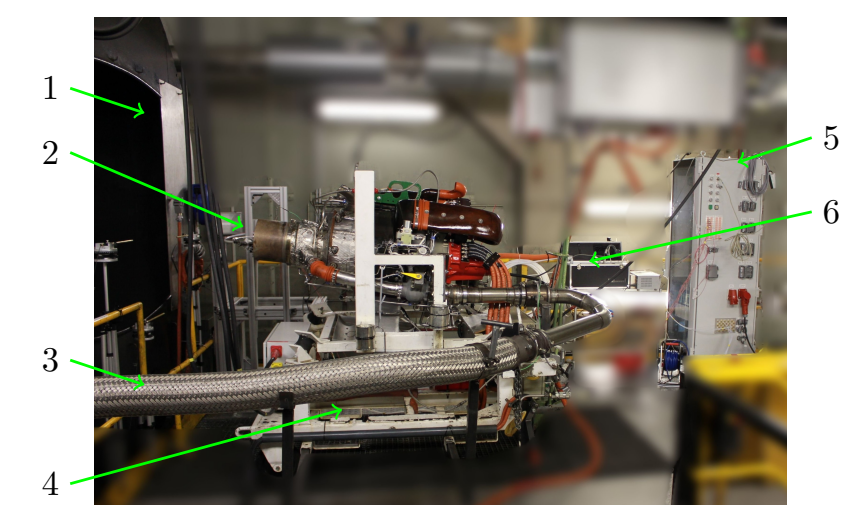

Fig. 1. EXPERIMENTAL SETUP: 1: Exhaust duct, 2: Exhaust probe, 3: Bleed air pipe, 4: Air inlet, 5: Control cabinet, 6: Flue gas analyzer

The test rig was located in a large room without acoustic insulation. The test cell volume was orders of magnitudes larger than the volume of the inlet air mass flow. The incoming flow was guided to the compressor inlet via a bell mouth at the bottom of the APU. The APU exhaust duct $\left(D_{e x} \approx 240 \mathrm{~mm}\right)$ opened to the test rig exhaust duct with an opening diameter of $2.5 \mathrm{~m}$. As the APU exhaust duct was not flanged to the test rig duct, the exhaust mass flow formed an open jet. This design was, for the exhaust emissions, comparable to an open field experiment. The bleed air produced by the load compressor flowed into a bleed control valve (BCV), which controled the amount of air delivered to the aircraft system and the air discharge to the APU exhaust duct. On the test rig, the air normally designated for the aircraft flowed through a flexible hose and measurements of bleed air properties occurred in this line. Subsequently, the bleed air disposed into the exhaust duct, downstream of exhaust properties measurements. As previously described, the load section was designed with variable inlet 
guide vanes. For the load point with no bleed air usage, the vanes were adjusted so that a minimum bleed air was produced and a compressor surge was prevented. The quantity of this minimum bleed air mass flow was unknown. This mass flow was then discharged into the APU exhaust. The electric load was adjusted by switching between different resistors at a load bank, which was placed outside the test facility.

The tested APU was certified for aviation, therefore no test equipment was installed inside the APU. The measurements were conducted after maintenance in the process of recommissioning. All measured properties are shown in Fig. 2. Calculated properties are listed and marked with an apostrophe. No commercially available mass flow meter was used for the determination of the inlet air mass flow, as no modification on the test facility or APU inlet could be implemented. Properties marked in gray were collected with a sampling rate of $1 \mathrm{~Hz}$ for five minutes. The black properties were logged by LHT and were only measured once. The single measurements were performed five minutes after a change in load consumption to allow for stationary conditions. The exhaust gas temperature changed to the new value within five seconds after a change in load, therefore signaling a sufficient wait time. During the five minutes of stationary condition there are temperature fluctuations of $0.5 \%$. Since the fluctuation occurred for all measured properties marked in gray, they were averaged over 4 minutes intervals.

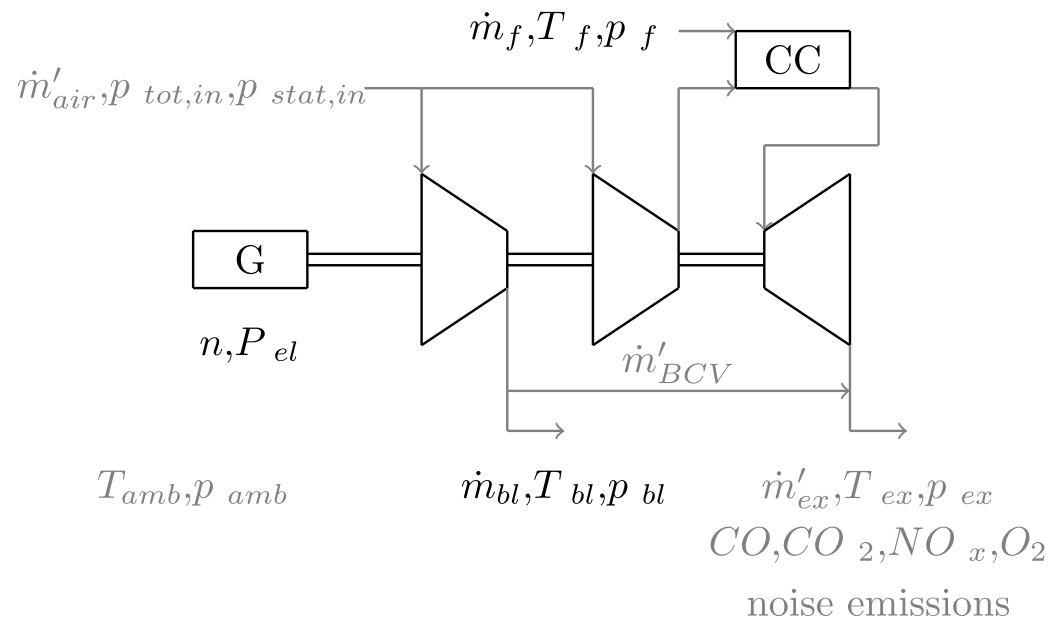

Fig. 2. PROCESS FLOW DIAGRAM WITH MEASURED AND CALCULATED PROPERTIES

The setup of the exhaust gas pressure and temperature sensors, as well as the probe are shown in Fig. 3. Cooling air kept the probe tip at a fixed temperature of $120^{\circ} \mathrm{C}$. The used pressure sensors (PXM319) were manufactured by OMEGA Engineering Inc. and had a pressure range of $350 \mathrm{mbar}$ to $20 \mathrm{bar}$. The temperature was measured using type $\mathrm{N}$ thermocouples, manufactured by TC Mess und Regeltechnik GmbH. Behind the exhaust gas outlet, temperature and pressure sensors were installed at a distance of $10 \mathrm{~cm}$. At the same position, an exhaust gas sample was simultaneously collected. The extracted exhaust gas was directed through a heated hose $\left(120^{\circ} \mathrm{C}\right)$ into the flue gas analyzer. The IMR 2000, manufactured by M\&C TechGroup Gentics $\mathrm{GmbH}$, used electrochemical sensors for measuring of $\mathrm{O}_{2}, \mathrm{CO}, \mathrm{NO}$ and $\mathrm{NO}_{2}$. The $\mathrm{CO}_{2}$ content was calculated, as a function of the $\mathrm{O}_{2}$ content and the amount of burned fuel. The emission values were collected and logged with the same data acquisition device and time stamp as all other parameters. The accuracy of the used measuring equipment is shown in Tab.1.

The test campaign involved the full spectrum of feasible power load and bleed air mass flow combinations. The ranges of the tested electric loads and bleed air mass flows are shown in Tab. 3 (Results). Twenty-five combinations were tested, which made it possible to adjust the five different electric loads in each case to the five utilizable bleed air mass flows. The emissions shown in this paper were determined using Jet A-1 fuel. To identify the fuel properties, the kerosene was analyzed in a gas chromatograph, as the refinery certificate of quality was not available. The kerosene sample was compared with kerosene analyzed beforehand, of which $85 \%$ of the molecule species were determined. The comparison of spectrum demonstrated a match. Therefore, the properties of this standard kerosene $\left(M_{f}=167.3 \mathrm{~kg} / \mathrm{mol}, H=43260 \mathrm{~kJ} / \mathrm{kg}, A F R=14.67\right)$ were used. In the following, $\mathrm{C}_{12} \mathrm{H}_{23}$ was used as a Jet A-1 surrogate for analyzing the measurement results.

The ambient conditions were measured at a distance from $1.5 \mathrm{~m}$ at the control cabinet. Ambient temperature and pressure remained constant at $T_{a m b}=10.2^{\circ} \mathrm{C}$ and $p_{a m b}=1.014 \mathrm{bar}$. The measured rotor speed was constant for all load points at $n=49306 \mathrm{rpm}$. Furthermore, the maximal shaft output provided for the generator (24000 rpm) was reported in [2], giving a gear ratio of roughly $1: 2$. 


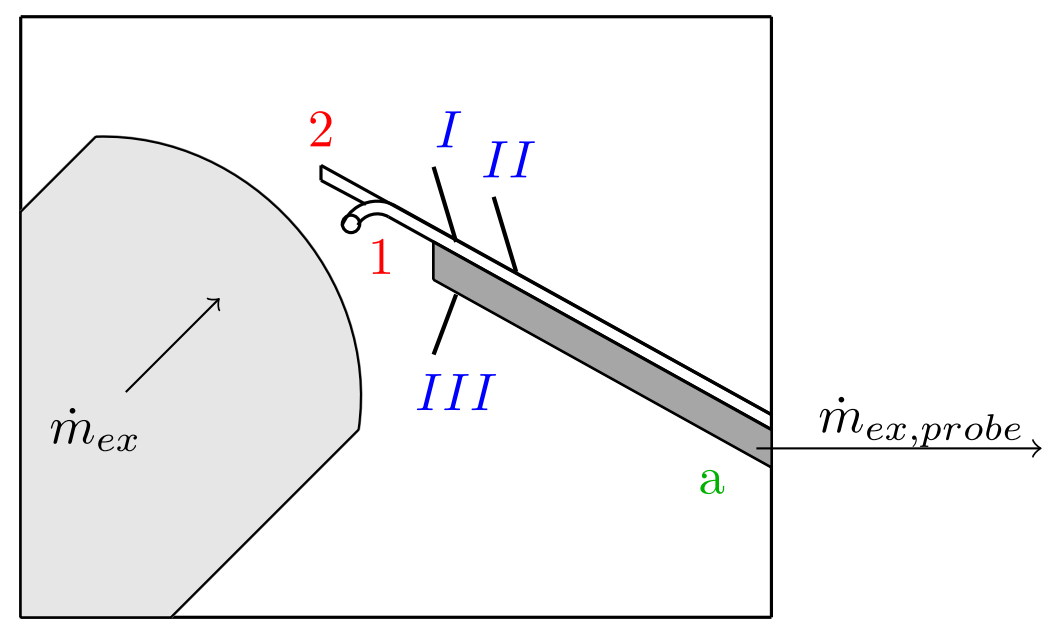

Fig. 3. SETUP OF EXHAUST GAS PROPERTY MEASUREMENT; Exhaust gas probe $=\mathrm{a}, p_{\text {tot }}=1, p_{\text {stat }}=2, T_{\text {ex }}=\mathrm{I}$, II, III

\section{Setup for acoustic measurements}

In order to obtain relevant noise data for the frequency content and sound pressure level of the APU, taking into account the - in terms of acoustic requirements - rather insufficient setup conditions, four high quality condenser microphones (type G.R.A.S. 40BP with pre-amplifier 26AC) were placed downstream of the APU exit. Three of them were located $60 \mathrm{~cm}$ downstream of the exhaust pipe trailing edge, well outside the shear region of the exhaust gas jet. Looking from aft onto the exhaust, these microphone positions are called "left", "center"(below the APU) and "right". A fourth microphone was placed in the downstream chamber below the chimney of the facility. The data was acquired with an OROS36 data acquisiton system (24 bit resolution) at a rate of $51.2 \mathrm{kHz}$. Single spectra were averaged over a 60 second time frame with only a Hanning window directly applied during the FFT (no A-weighting function or other corrections applied). Usually, three of those readings were recorded per operating point (about 5 minutes of stable operation) and for further data presentation, averaged. An illustration of the microphone installation is shown in Fig. 4.

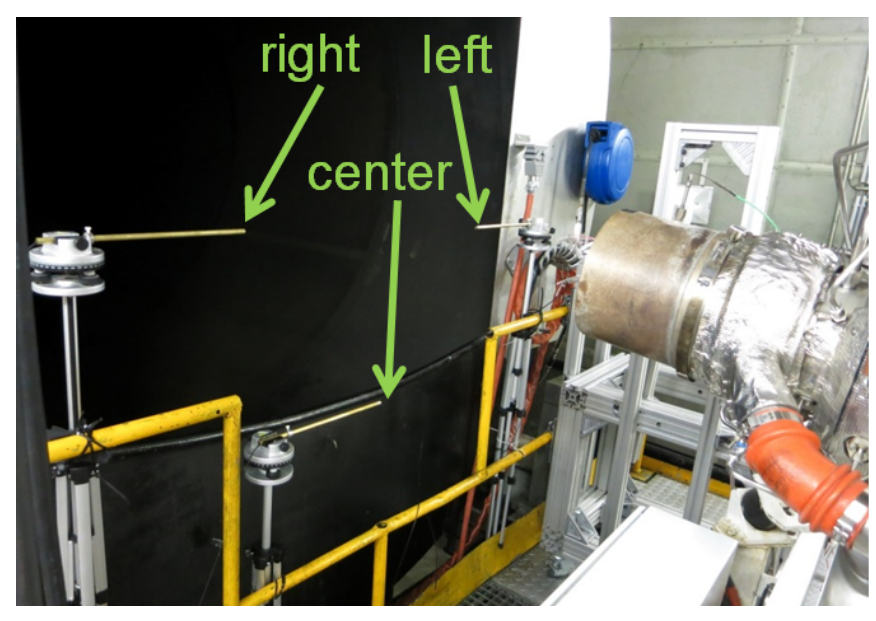

Fig. 4. POSITION OF MICROPHONES

\section{RESULTS}

The results of the measuring campaign are presented in the following section and are divided into the corresponding properties. 


\section{Thermodynamic Properties \\ Mass flows}

During the experiment, only the bleed air and fuel mass flows were measured. Due to the test rig set up, no measurement of incoming air flow was possible. To evaluate the air mass flow, a system mass balance was formed and therefore, the exhaust mass flow was calculated. To determine the exhaust gas mass flow, a carbon balance equation was formed between the fuel inlet and exhaust as proposed in ([12], page 83). With the exception of the $\mathrm{CO}_{2}$ content of air, all $\mathrm{CO}_{2}$ and $\mathrm{CO}$ exhaust emissions resulted from the conversion from fuel to exhaust gas. Therefore, the carbon mole fraction of the exhaust gas can be compared with the fuel carbon mole fraction. Previous analysis of other gas turbine rigs have shown that the carbon balance approach gives very reliable exhaust gas mass flows [13]. The carbon balance equation was formed using the carbon mole fraction of $\mathrm{C}_{12} \mathrm{H}_{23}$, as the Jet A-1 surrogate $\left(x_{f}=12 \mathrm{molC} / \mathrm{mol}\right.$ Kerosene), and the mole fraction of carbon in the exhaust gas $\left(x_{e x}=\mathrm{molC} / \mathrm{mol}\right.$ Exhaust Gas), as shown in Eqn. (1).

$$
\begin{array}{r}
\text { Carbon }_{\text {fuel }}=\text { Carbon }_{\text {exhaust }} \\
x_{f}=x_{\mathrm{C}_{12} \mathrm{H}_{23}}=\mathrm{v}_{d}\left(x_{\mathrm{CO}_{2}}+x_{\mathrm{CO}}+x_{\mathrm{UHC}}\right)
\end{array}
$$

With the dry exhaust gas amount in mol Exhaust Gas per mol Kerosene $\left(v_{d}\right)$, the mole masses of kerosene and exhaust gas, as well as the fuel mass flow the exhaust gas mass flow can be calculated according to Eqn. (2). Thereby, the exhaust gas molar mass $\left(M_{e x}\right)$ is a function of the exhaust gas composition.

$$
\dot{m}_{e x}=v_{d} \dot{m}_{f} \frac{M_{e x}}{M_{f}}
$$

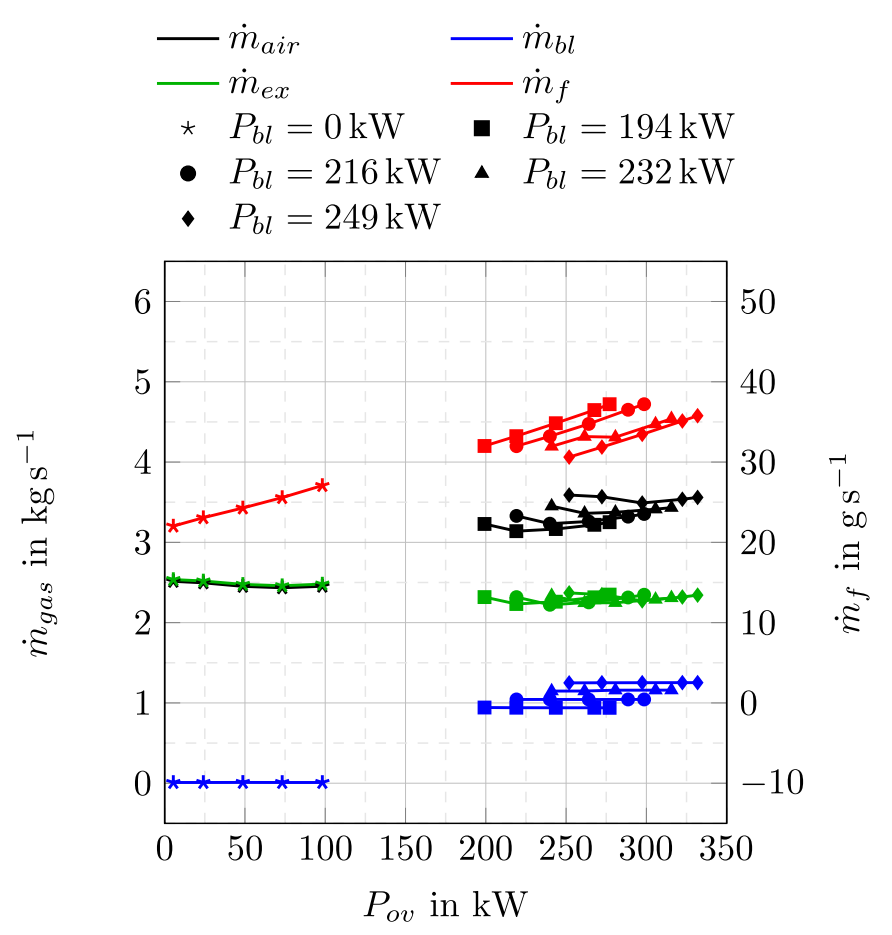

Fig. 5. MEASURED AND CALCULATED MASS FLOWS

Equation (1) neglects the $\mathrm{CO}_{2}$-content of air which is an acceptable simplification, as the resulting error is less than $0.04 \%$. The resulting error, due to the unmeasured UHC content of the exhaust gas, can only be estimated. According to other APU exhaust gas measurements [1], UHC has a marginal bigger influence, as the resulting error is around $0.8 \%$ for the assumption of all UHC molecules being $\mathrm{C}_{12} \mathrm{H}_{23}$. All calculated and measured mass flows are shown in Fig. 5 and plotted against the overall power output $\left(P_{o v}\right)$. The determination of $P_{o v}$ and the bleed air power $\left(P_{b l}\right)$ is described in the following section "Power and Efficiency". 
The gaseous mass flows are plotted on the left y-axis, whereas the fuel mass flow is on the right y-axis, above the overall power output on the x-axis. For the definition of the $P_{o v}$, see Eqn. (4). Note that the bleed air mass flow is directed into different piping, so the exhaust gas mass flow does not contain the bleed air, with exception of the minimal bleed air waste mass flow $\left(\dot{m}_{B C V}\right)$. There is a vast difference in all mass flows between the states with and without bleed air usage. For $P_{b l}=0 \mathrm{~kW}$, the values of $\dot{m}_{a i r}$ and $\dot{m}_{e x}$ are very similar, as all air entering the APU left the system via the exhaust. In this case, the consumption of kerosene is around $30 \%$ lower than if bleed air was used. As the fuel consumption was the basis for the calculation of the thermal power $\left(P_{t h}\right)$, no additional information, in comparison to chapter "Power and Efficiency", can be gained. No impact on $\dot{m}_{\text {air }}$ can be seen for a rising electric load $\left(P_{e l}\right)$, but the required amount of air rises with a rising bleed air load. At the same time, the exhaust gas flow remains nearly the same. The only vast change in exhaust gas mass flow can be seen during $P_{b l}=0 \mathrm{~kW}$. At these conditions, $\dot{m}_{e x}$ is higher compared to conditions with $P_{b l}>0 \mathrm{~kW}$, as the surge bleed air is added to the exhaust flow. Neither a rising $P_{e l}$ or $P_{b l}$ have a clear effect on the exhaust gas amount, as the variation is smaller than the resulting error. Here, the influence of an operation at a defined rotational speed dominates the gas turbine performance and is stronger than the influence of a shift in operating point in the turbo compressor map.

The minimal bleed air waste mass flow $\left(\dot{m}_{B C V}\right)$ guided from the BCV to the exhaust could not be calculated. However, from the difference in exhaust gas flows (Fig. 5), as well as the differing BCV position (Tab. 2), estimating $\dot{m}_{B C V}$ is possible. For the estimation of $\dot{m}_{B C V}$ via the BCV position, the assumptions of similar counter pressure for both outlets were made. Additionally, an angle-dependent split was assumed. The estimated values align with the values given in [3] and are shown in Tab.2 This mass flow estimation should be reviewed in a numerical cycle simulation.

\section{Power and Efficiency}

A definition for an overall power output is necessary to calculate an APU efficiency. In addition to the electric power, a bleed air power output has to be defined. The bleed air or pneumatic power $\left(P_{b l}\right)$ is defined as the power drawn by the compressor, which results from the use of bleed air, as shown in Eq. 3

$$
P_{b l}=\dot{m}_{b l} \Delta h_{a}=\dot{m}_{b l} c_{p}\left(T_{b l}-T_{a m b}\right)
$$

From the calculated $P_{b l}$, the overall power output was determined and used to calculate the APU efficiency $\left(\eta_{o v}\right)$ :

$$
P_{o v}=P_{b l}+P_{e l} \hookrightarrow \eta_{o v}=\frac{P_{o v}}{P_{t h}}
$$

The electric power $\left(P_{e l}\right)$ was measured, whereas the thermal input power $\left(P_{t h}\right)$ was calculated via $P_{t h}=\dot{m}_{f} H_{f}$. From the measured $P_{e l}$ and calculated $P_{t h}$ the electrical efficiency was determined:

$$
\eta_{e l}=\frac{P_{e l}}{P_{t h}}
$$

The corresponding values of bleed air load and bleed air mass flow, as well as the compressor power $\left(P_{c p}\right)$ are shown in Tab. 3. $P_{c p}$ is a function of $\dot{m}_{b l}, \dot{m}_{B C V}, p_{b l} / p_{a m b}, T_{a m b}$ and $\eta_{i s}$. The isentropic efficiency $\left(\eta_{i s}\right)$ was calculated as a function of $T_{b l}$ and $T_{a m b}$.

In Fig. 6, the thermal power is plotted against the bleed air power. For $P_{e l}$ smaller than $24 \mathrm{~kW}$, measurements were taken at $P_{b l}=237 \mathrm{~kW}$ instead of $232 \mathrm{~kW}$. Take note that $P_{b l}=0 \mathrm{~kW}$ is not displayed in this graph. It is clear from Fig. 6, that if $P_{e l}$ is kept constant no clear effect on $P_{t h}$ can be seen for increasing $P_{b l}$ as it remains nearly constant. Changing $P_{b l}$ results in a variation of $P_{t h}$ of only $5 \%$. For the constant $P_{t h}$ at $P_{b l}=194 \mathrm{~kW}$ and $216 \mathrm{~kW}$, the position of the variable inlet guide vanes (VIGV) remains the same (Tab. 2). The bleed air pressure and temperature simultaneously stay constant as well (see Fig. 10), where no change in compressor power and compressor mass flow was seen. The $P_{t h}$ was at a minimum at a bleed load of $232 \mathrm{~kW}$. The VIGVs were open the widest for this load and the compressor power was at a low point. At a further increased load of $P_{b l}=249 \mathrm{~kW}$, the VIGVs closed again and $P_{c p}$ increased. As the isentropic compressor efficiency depends on the VIGV position ( [14], page 174), the maximum efficiency was expected at $P_{b l}=232 \mathrm{~kW}$, where the VIGVs were opened the widest (Tab. 2).

Figure 7 depicts a $P_{t h}$ dependence on $P_{e l}$. There is a vast difference in thermal input power $\left(P_{t h}\right)$ for load points with and without bleed air usage, as $P_{t h}$ is $30 \%$ lower for cases with $P_{b l}=0 \mathrm{~kW}$. For constant bleed air load, a rise in $P_{e l}$ causes an increase in $P_{t h}$. The gradient is linear and similar for all $P_{b l}$. A rise in $P_{b l}$ equals a decline in $P_{t h}$ until the graph reaches a low 


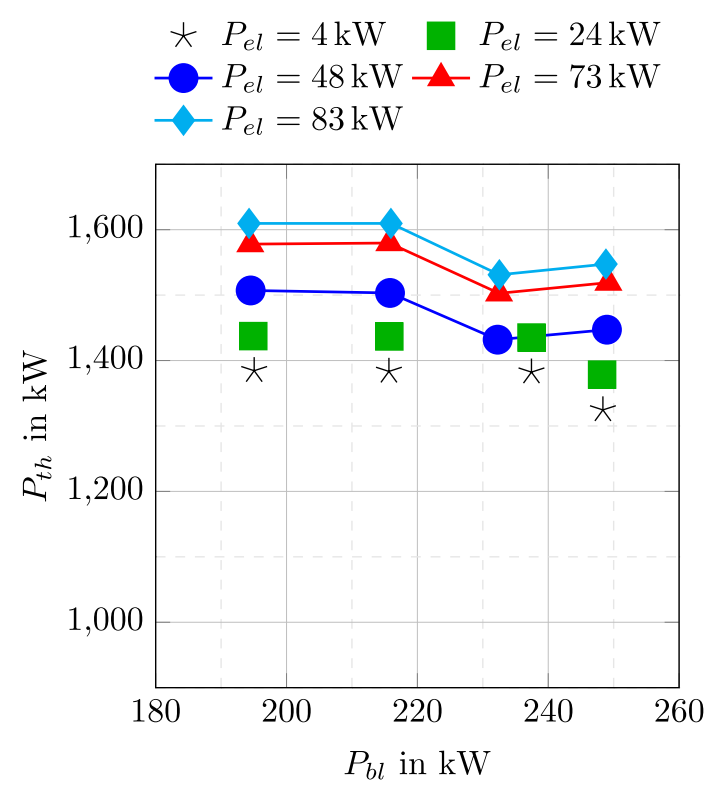

Fig. 6. INFLUENCE OF $P_{b l}$ ON $P_{t h}$ FOR CONSTANT $P_{e l}$

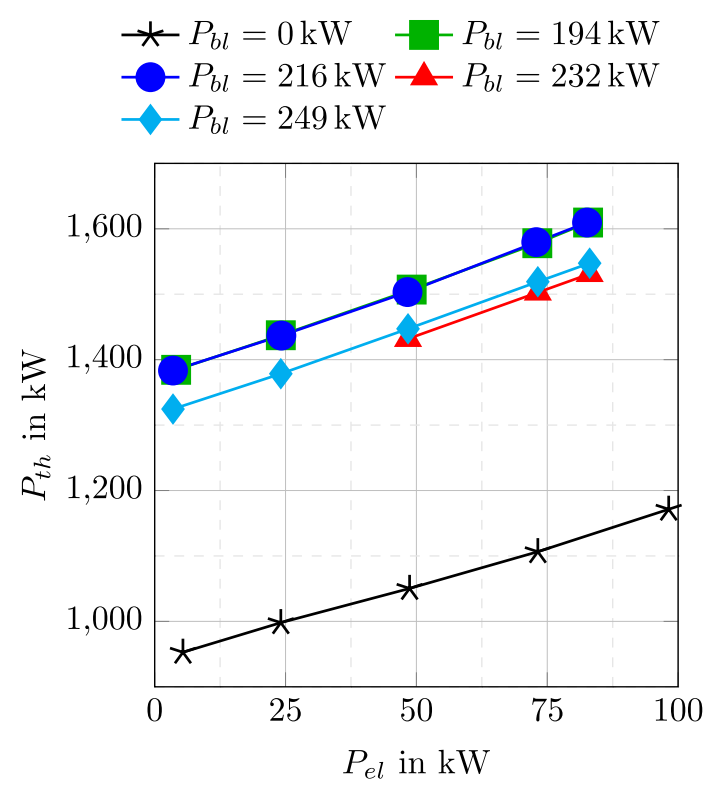

Fig. 7. INFLUENCE OF $P_{e l}$ ON $P_{t h}$ FOR CONSTANT $P_{b l}$

point at $232 \mathrm{~kW}$. Both Figures suggest that the design point for the APS3200 is close to the bleed air load of $232 \mathrm{~kW}$, which equals a bleed air mass flow of $1.15 \mathrm{~kg} / \mathrm{s}$. Another indicator for the design point near $m_{b l}=1.15 \mathrm{~kg}$ are the declarations from [2]. According to manufacturer information, the maximum bleed air power available is $m_{b l}=1.2 \mathrm{~kg} / \mathrm{s}$ at $? p=2.9 \mathrm{bar}$ and $T=232^{\circ} \mathrm{C}$ at $P_{e l}=83 \mathrm{~kW}$. However, no specific declaration of a design point is made in [2] or any other open accessible source.

The overall and electric efficiency are plotted against the overall power in Fig. 8. Since the efficiencies of the cases with bleed air load are close together, only the minimum and maximum bleed air load are shown. Furthermore, no overall efficiency is shown for $P_{b l}=0 \mathrm{~kW}$, as $\eta_{o v}$ equals $\eta_{e l}$. The maximum overall efficiency $\eta_{o v}=21.4 \%$ is attained for $P_{b l}=249 \mathrm{~kW}$ and $P_{e l}=83 \mathrm{~kW}$, while the minimum of $\eta_{o v}=0.6 \%$ is reached during the no bleed air case at the lowest usable electric load of $4 \mathrm{~kW}$. The highest electric efficiency $\eta_{e l}=8.4 \%$ is reached at $P_{e l}=99 \mathrm{~kW}$ and $P_{b l}=0 \mathrm{~kW}$. The overall efficiency $\left(\eta_{o v}\right)$ reaches a maximum of $21.4 \%$, which is very low compared to other micro gas turbines (MGT) where the electric efficiency is around $30 \%$ [15]. Those MGTs are usually built with a recuperator, which offers the possibility of increasing efficiency with cycle modifications. 


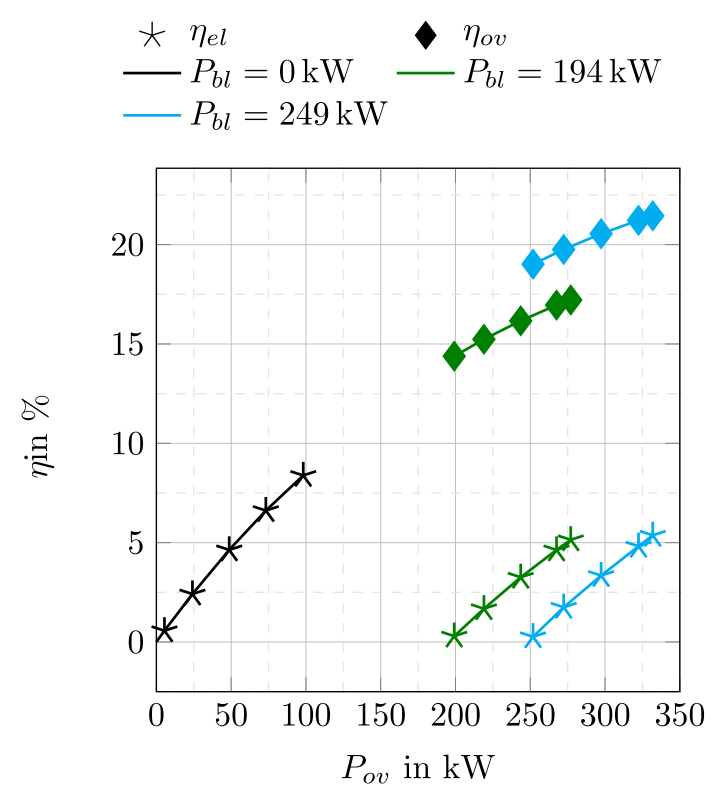

Fig. 8. INFLUENCE OF $P_{o v}$ ON $\eta_{o v}$ AND $\eta_{e l}$

\section{Pressure and Temperature}

Pressure and temperature measurements were only possible in the inlet or exhaust flows, as no internal modification to the APU was feasible. In Fig. 9, the influence of overall power output on the exhaust gas temperature $\left(T_{e x}\right)$ is mapped. If Eqn. (4) is taken into account, a rise in $P_{e l}$, which produces a higher $T_{e x}$, can be seen. A rise in $P_{b l}$, however, has only a small effect, as $T_{e x}$ decreases by $15 \mathrm{~K}$ between $P_{b l}=194 \mathrm{~kW}$ and $249 \mathrm{~kW}$. Again, a difference between $P_{b l}=0 \mathrm{~kW}$ and bleed air usage is evident. The lower exhaust temperature is due to the significantly leaner combustion at $P_{b l}=0 \mathrm{~kW}$ ( $\lambda_{g l}$ is shown in Tab. 47. The variation of $T_{e x}$ for a constant $P_{o v}$ is due to two effects caused by the bleed air mass flow directed from the bleed control valve to the exhaust $\left(\dot{m}_{B C V}\right)$. The additional power needed to drive the load compressor, when part of the flow is bled to the exhaust, leads to a higher $T_{e x}$. A decline in $T_{e x}$ is caused afterwards by the mixing of the exhaust gas flow with $\dot{m}_{B C V}$. According to Fig. 9, the mixing has a lesser effect than the higher compressor power. At $P_{b l}=0 \mathrm{~kW}$, the BCV is closed $\left(0^{\circ}\right)$, and all produced bleed air is directed into the exhaust. For all other $P_{b l}$ values, the BCV settings are shown in Tab. 2. The hot exhaust gas flow has a great amount of exergy. Consequently, a waste heat utilization concept should be considered if the APU efficiency should be increased.

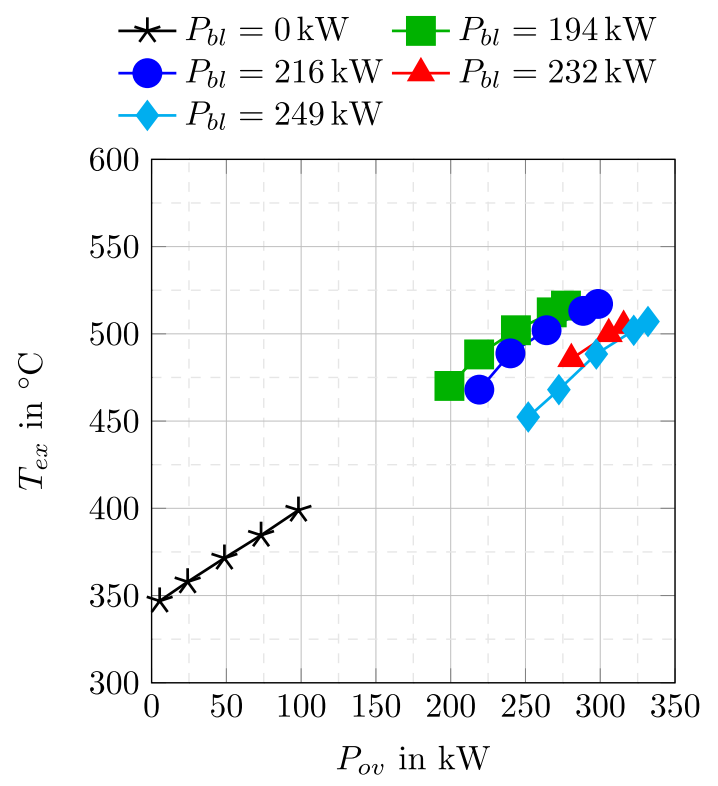

Fig. 9. INFLUENCE OF OVERALL POWER OUTPUT ON $T_{e x}$

GTP-17-1390 / Siebel

(C2017 by ASME. This manuscript version is made available under the CC-BY 4.0 license http://creativecommons.org/licenses/by/4.0/

The original publication is available at $\mathrm{http}: / / \mathrm{dx}$.doi.org/10.1115/1.4038159 
Figure 10 depicts the characteristics of bleed air properties plotted against bleed air power. A change in $P_{e l}$ has no influence on these properties and is therefore, not considered. Both $T_{b l}$ and $p_{b l}$ display a similar trend. For a rise in $P_{b l}$ from $194 \mathrm{~kW}$ to $216 \mathrm{~kW}$, no influence can be seen. If the bleed air load is further increased to $232 \mathrm{~kW}$, a sudden drop in $T_{b l}$ and $p_{b l}$ occurs, which further increases for a bleed air load of $249 \mathrm{~kW}$. This behavior corresponds to the behavior of the thermal load (see Fig. 6) and the VIGV position (Tab. 22), which stays unchanged for the bleed air load points of 194kW and $216 \mathrm{~kW}$. Furthermore, the bleed air properties follow the compressor map shown in [2]. Bleed air pressures between $p_{b l}=3.5$ bar and $3.9 \mathrm{bar}$ were seen, whereas $T_{b l}$ varied between $205^{\circ} \mathrm{C}$ and $213.7^{\circ} \mathrm{C}$. The gained properties match the information about bleed air pressures between 2.9 bar and 3.9 bar described in [2].

\section{$\simeq p_{b l}$ in bar $-T_{b l}$ in ${ }^{\circ} \mathrm{C}$}

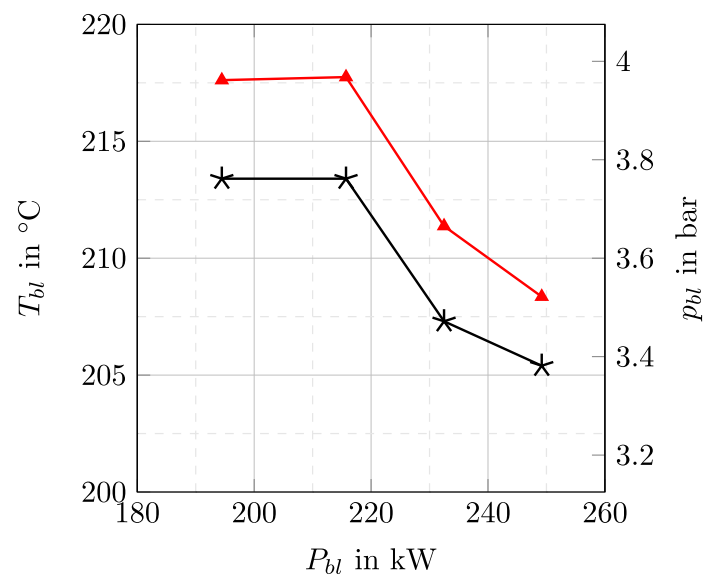

Fig. 10. IMPACT OF BLEED AIR POWER OUTPUT ON $T_{b l}$ AND $p_{b l}$ FOR CONSTANT $P_{e l}=73 \mathrm{~kW}$

\section{Exhaust Gas Emissions}

Exhaust gas emissions, especially CO and NOx, of a state of the art APU are of interest due to a lack of consistent airport or up to date stationary engine data. Additionally, the allowable exhaust gas emissions for APUs are not regulated by the ICAO [7]. To compare the collected emission data to recent regulations of gas turbines, the exhaust emission standards for stationary power supply, stipulated by the German Government in "Technische Anleitung zur Reinhaltung der Luft" (TA-Luft) [16], were used. The TA-Luft regulates the exhaust gas emissions for stationary gas turbines of different enginepower classes and fuels in Germany. To generate comparable data, all presented exhaust gas emissions were normalized with $15 \mathrm{vol} \% \mathrm{O}_{2}$ at dry conditions, as proposed in [16]. In the following sections, the influence of a varying overall power output on the NOx and $\mathrm{CO}$ emissions is presented. The $\mathrm{CO}_{2}$ emissions were nearly constant for all measured overall power outputs at $4.4 \mathrm{vol} \% @ 15 \mathrm{vol} \% \mathrm{O}_{2}$ and varied maximally within a range of $30 \mathrm{ppm}$. Therefore, no data for $\mathrm{CO}_{2}$ is shown in this paper.

\section{Carbon monoxide}

Figure 11 shows the $\mathrm{CO}$ emission profiles for the variation of overall power output. For cases with bleed air load, the $\mathrm{CO}$ emissions vary between $60 \mathrm{ppm}$ and $100 \mathrm{ppm}$. It is evident that the cases with $P_{b l}=0 \mathrm{~kW}$ have the highest emission values at about $140 \mathrm{ppm}$. The doubled value suggests that the measurements with no bleed air load can be described as "off design points". If bleed air is used a rise in electric load causes a decrease in CO emissions. However, a higher bleed air load increases the emission value. To characterize the combustion reaction a global air number $\left(\lambda_{g l}\right)$, which is the reciprocal of the equivalence ratio, is defined in Eq. 6. 6 .

$$
\lambda_{g l}=\frac{\dot{m}_{a i r}-\dot{m}_{b l}-\dot{m}_{B C V}}{\dot{m}_{f} A F R}
$$

In Tab. $4 \lambda_{g l}$ is displayed for different load points. For a rising $P_{e l}$ and a constant $P_{b l}$, it becomes evident, that the global air number decreases. According to [17] if the air number declines simultaneously to decreasing $\mathrm{CO}$ emissions, the combustion takes place in a lean mixture. For this branch of the $\mathrm{CO}_{2}$ profile, the combustion is dominated by non-equilibrium 


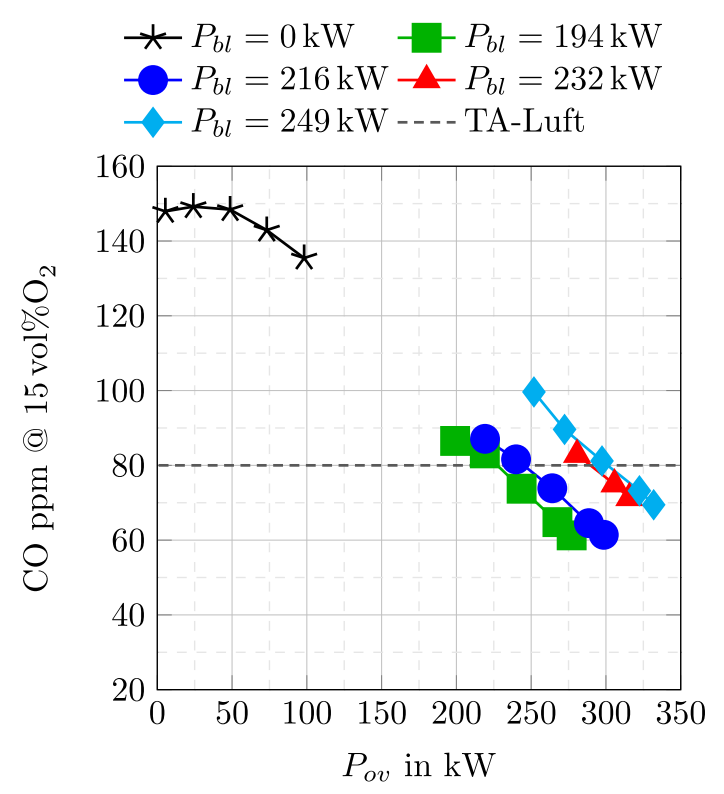

Fig. 11. INFLUENCE OF $P_{o v}$ ON CO EMISSIONS FOR DIFFERENT BLEED AIR AND ELECTRIC LOADS

effects [18], due to an insufficient residence time in the combustion chamber. At richer air numbers, the $\mathrm{CO}$ concentration in the exhaust gas decreases, the flame speed rises and the combustion takes place in a smaller volume. The smaller combustion volume leads to more complete combustion and less quenching occurs at the dilution air zones. While these are generally valid conclusions for gaseous combustion, for liquid fuel combustion, the influence of fuel atomization and evaporation has to also be considered. Especially at conditions with bad atomization and therefore great mean drop size, the influence of fuel evaporation has to be considered, as a great proportion of the combustion volume is then filled with evaporating fuel. Thus, less volume is available for the chemical reaction [17]. If $P_{e l}$ is kept constant and $P_{b l}$ is increased, a leaner mixture is present and a rise in $\mathrm{CO}$ emissions can be seen.

The CO emissions for $P_{b l}=0 \mathrm{~kW}$ exceed the TA-Luft regulations limit of $80 \mathrm{ppm}$ by $60 \mathrm{ppm}$. As these cases have a thermal load of less than 70\%, TA-Luft regulations are not comparable. For all other load points, TA-Luft may be used as a reference and the measured emission values are within or slightly above the limit. In comparison to $\mathrm{CO}$ emission indices found in literature the measured values are well within the accepted range and are between the values published by the ICAO [7] and Kinsey et al. [4].

\section{Nitrogen oxide}

The NOx emission values were calculated by addition of the measured $\mathrm{NO}$ and $\mathrm{NO}_{2}$ emission values. In Fig. 12, the NOx values are plotted against the overall power. The off design case of no bleed air load displays the highest emission levels with concentrations of $100 \mathrm{ppm}$. However, the difference between the bleed air and no bleed air cases is less significant. The little scattering in NOx emissions as well as their high measured value are congruent with the spray combustion phenomena. Spray combustion takes place in fuel droplet surrounding areas. Combustion in these areas is often near-stoichiometric, resulting in higher NOx formation [17]. Even though the change in total value is smaller than the error of measurement, a consistent trend for the influence of $P_{e l}$ and $P_{b l}$ can be determined. An increase in electric power causes a decrease in NOx emissions, an effect similar to the $\mathrm{CO}$ emissions, although less pronounced. The influence of a change in bleed air load is in the same order, however a rise in bleed air load increases the NOx emissions. It can be seen that the NOx emissions are above the limits of TA-Luft for all load points and in a range between 90 and $102 \mathrm{ppm}$, which falls within emission indices between 2.1 and $4.3 \mathrm{~g}$ pollutant $/ \mathrm{kg}$ fuel. The NOx emissions exceed the limit of $73 \mathrm{ppm}$ for stationary turbines by at least $20 \%$. The measured values match the IACO values [7], but exceed the values given by Schäfer for another APS3200 [19].

To decrease the exhaust emissions a variable speed engine concept should be considered, as a load adapted mass flow would lead to better combustion mixtures at off design points.

\section{Noise Emissions}

Acoustic results for the two major operating conditions (with and without bleed air) are shown in Fig. 13. For the case without bleed air - which is shown in the upper plot - no bleed air is guided through the bleed air dump pipe visible in the foreground of Fig. 1. However, a small amount (which is produced in order to prevent compressor stall) is guided by the BCV to the main exhaust and mixed with the burned gas. Microphones on either side of the exhaust ("left" and "right") 


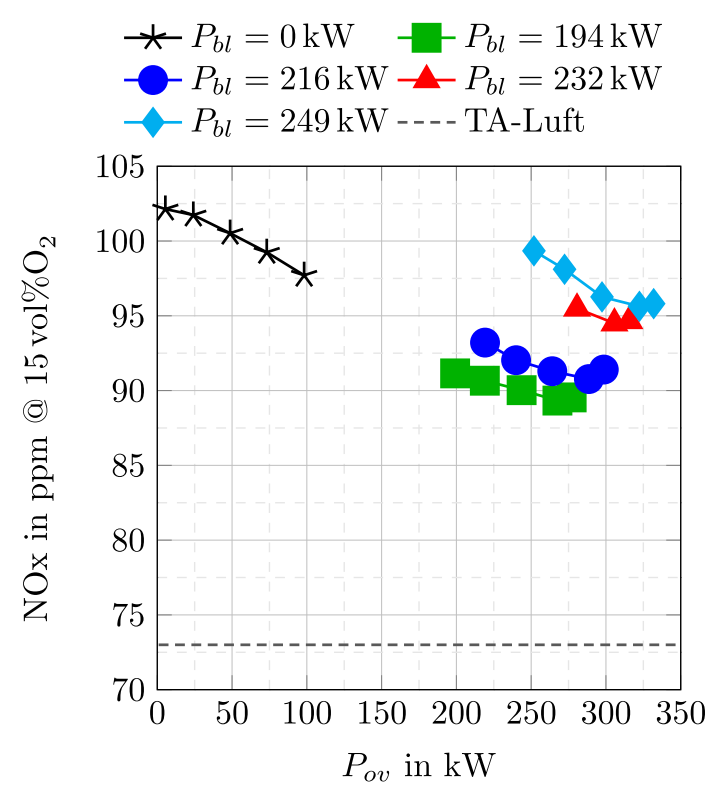

Fig. 12. INFLUENCE OF $P_{u t}$ ON NOx EMISSIONS FOR DIFFERENT BLEED AIR AND ELECTRIC LOADS

measured the same sound pressure over the full frequency range. The microphone below ("center") measured a smaller value due to the inclination of the APU and the resulting larger distance to the exhaust gas jet. The microphone in the exhaust gas chamber exhibits a larger peak at $50 \mathrm{~Hz}$ due to mains interference. Additionally, the SPL is much lower. The overall sound pressure level is dominated by low-frequency broadband noise between 20 and $300 \mathrm{~Hz}$ (which shifts also slightly with operating point (not shown here). The region around $1 \mathrm{kHz}$ is also slightly load dependent with a tonal peak near $1400 \mathrm{~Hz}$ for the "no bleed flow" cases. The distinct frequencies at 9 and $18 \mathrm{kHz}$ are multiples of the shaft speed (11 times and 22 times, respectively) most likely caused by an interference of turbine rotor 1 (37 blades) and the guide vanes of turbine rotor 2 (26 vanes).

In the lower plot, the spectra change significantly when bleed air is produced (here $1.25 \mathrm{~kg} / \mathrm{s}$ ) and disposed through the pipe: The flow noise in the pipe disturbs the measurement of the nearest microphone ("right") Therefore, for subsequent comparison of operating points with different load states only data from the undisturbed microphone ("left") was used. The bleed air was dumped via a sudden area change into the large chamber downstream of the rig (presumably getting close to sonic conditions at the outlet), thereby producing a large amount of jet noise, which is clearly visible on the chamber microphone.

The load variation (as measured by the undisturbed microphone) is shown in Fig. 14. For the variation of bleed air mass flow, only the operating point with "no bleed air" significantly differs from higher SPL levels in the low frequency broad band range. This might be partly caused by the small amount of remaining bleed air, which is mixed by the BCV into the main exhaust gas path. However, a noise increase caused by this off-design operating condition is also a likely explanation for the observed behavior.

In the lower plot of Fig. 14, the variation of electric load is shown while running on constant (maximum) bleed air production. Again, the increased SPL for the low frequency region when no (electrical) load is present is clearly visible. Considering the marginal deviations between spectra of all other operating points with different electrical load, this emphasizes the importance of off-design-conditions for the overall noise generation.

The spectra shown above prove the necessity for effective damping of low frequency broadband noise. The muffler, usually attached to the APU, could not be assessed in terms of its noise reduction capabilities due to the limited size of the test bench. However, subsequent work will deal with the efficient damping of the exhaust noise - usually the strongest source during APU operation (depending on installation and point of observation, some noise is of course also radiated from the APU inlet of an aircraft).

\section{SUMMARY AND CONCLUSION}

Within this paper, an experimental investigation of a state of the art APU is presented. For the first time, thermodynamic properties as well as exhaust gas and noise emissions of an APU were simultaneously determined. The properties of a Pratt \& Whitney APS3200 were studied over the complete feasible range of operating conditions. Consequently, an extensive data set was collected, which enables numerical APS3200 cycle simulation validation.

Bleed air power was defined and an overall power determined. Additionally, the electric and overall efficiency were 

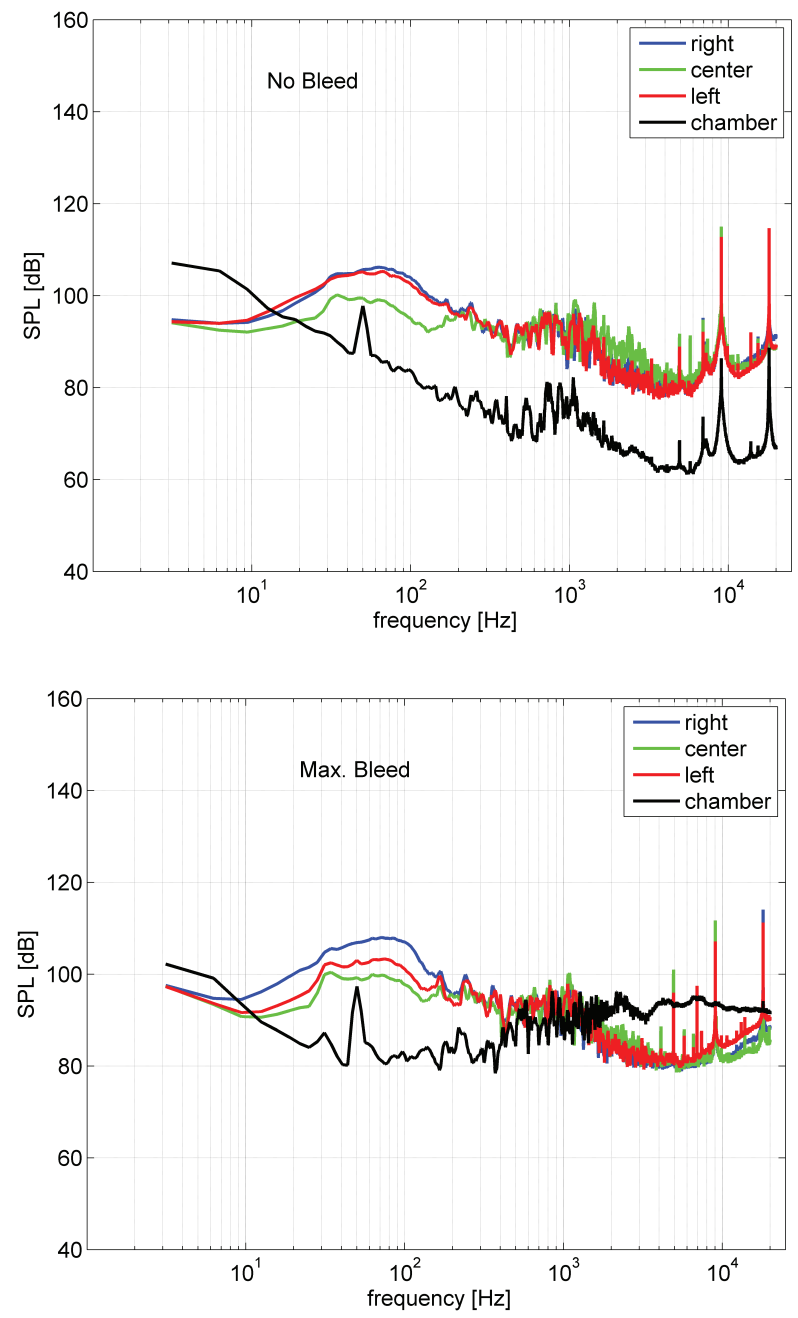

Fig. 13. SPECTRA OF ALL MICROPHONES FOR OPERATING POINT WITHOUT (UPPER) AND WITH BLEED AIR (LOWER PLOT)

calculated and presented as a function of load point. The influence of bleed air mass flow and electric load was studied by means of fuel consumption, exhaust gas temperature, bleed air properties and emission characteristics for a large operation window.

In general, APUs are characterized by a low overall and electric efficiency, which was also confirmed for the APS3200. A design point close to $P_{b l}=232 \mathrm{~kW}$ and $P_{e l}=83 \mathrm{~kW}$ was identified, where the overall efficiency reaches $20.6 \%$. The kerosene consumption is strongly influenced by the electric load, a smaller impact can be seen for a change in bleed air load. This is due to a nearly constant power consumption of the load compressor when bleed air is used. Furthermore, the exhaust gas temperature rose with higher electric power, whereas a higher bleed air mass flow led to a slight decrease. Bleed air pressure and temperature were highly affected by the consumed amount of bleed air. A strong influence of rising electric load was seen on the CO emissions, declining from $100 \mathrm{ppm}$ to $75 \mathrm{ppm}$ at $P_{b l}=249 \mathrm{~kW}$, whereas the change in bleed air load has a minor influence. In contrast, the NOx emissions were only slightly affected by either electric or bleed load, varying from 90 to $100 \mathrm{ppm}$. The results show that the operating conditions without bleed air load can be described as an off design point, as it has the lowest overall efficiency. Furthermore, the off design point was characterized by very high levels of both $\mathrm{CO}$ and NOx emissions.

During the noise measurements, an assessment of the overall noise level, its frequency content and the change of both with respect to the operating point was obtained. The results suggest a required muffler performance mainly in the low frequency region. The tonal components (strongest for 9 and $18 \mathrm{kHz}$ ) will be already significantly damped by atmospheric absorption when radiated into the free field. The results highlight the acoustic relevance of off-design conditions, which should be avoided during operation or taken into account for muffler design.

In the future, the electric efficiency of an APU will be more relevant, as the generation of electricity will be the main APU task for a more electric aircraft. Therefore, optimization of the APU process with higher overall and electric efficiency is required. Possible components are already installed in state of the art micro gas turbines. For example, recuperators are 

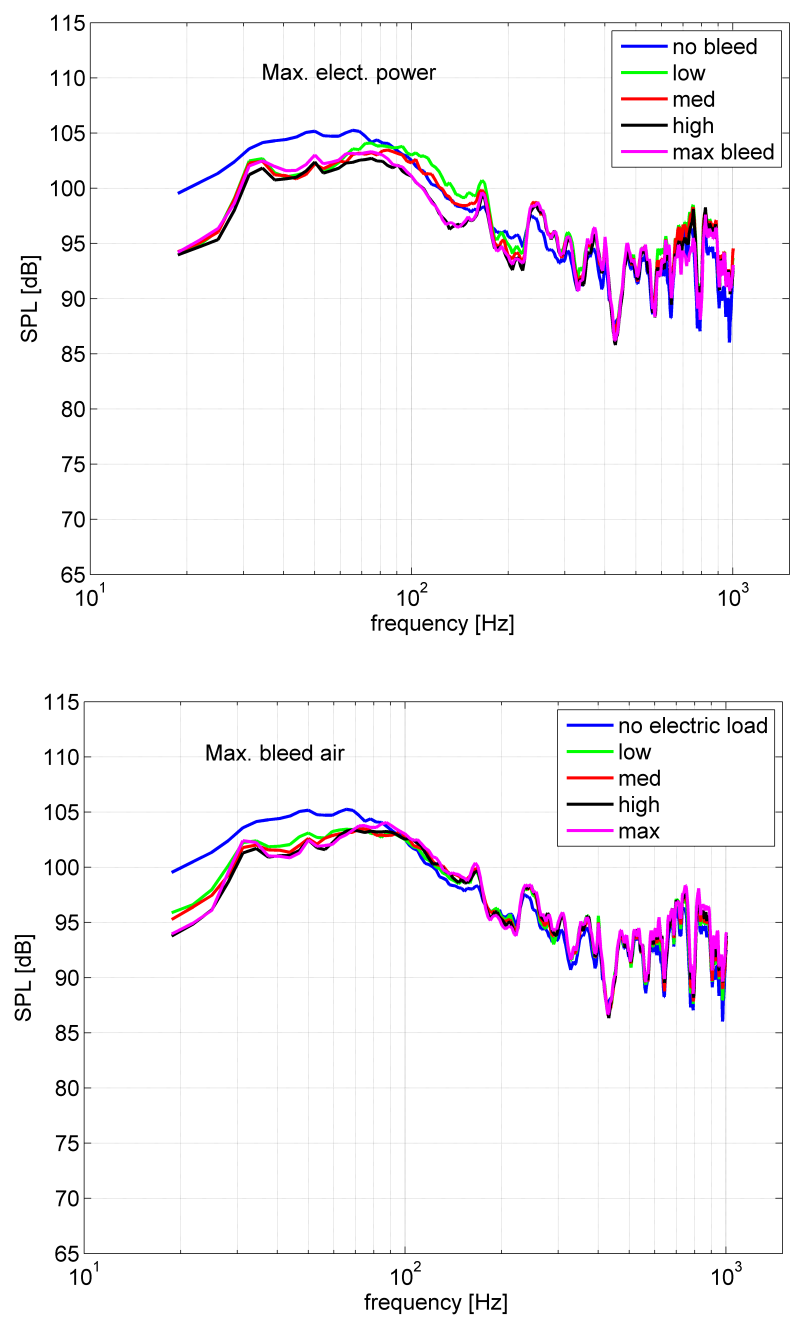

Fig. 14. SPECTRA OF UNDISTURBED MICROPHONE FOR LOAD VARIATIONS. UPPER PLOT: VARIED BLEED AIR (MAXIMUM ELECTRIC POWER), LOWER PLOT: VARIED ELECTRIC LOAD (MAXIMUM BLEED AIR)

used to preheat the compressed air entering the combustion chamber and consequently, reduce the fuel consumption. Direct coupling of APU exhaust and the ECS recovery heat from the APU exhaust gases could be another feasible approach. As weight is a critical property in an aircraft, a trade-off between efficiency gain and weight gain has to be determined depending on the imminent flight mission. The potential efficiency gain should be determined in a numerical cycle simulation. Furthermore, airports increasingly regulate APU usage to reduce APU emissions. Therefore, APU components which lower noise and exhaust gas emissions are desired. This need will further rise if the IACO introduces an official regulation. Hence, improvements in combustion chamber and muffler designs should be sought.

\section{Acknowledgements}

The experiments were conducted by courtesy of Lufthansa Technik AG. The authors would like to thank Oliver Schulz, Gerrit Sals and Arno Johannsen from Lufthansa Technik AG for their help and answers prior, during and after the experiments. For his commitment to this project a special thanks goes to Jürgen Roth.

\section{References}

[1] Fleuti, E., and Hoffmann, P., 2005. Aircraft APU Emissions at Zurich Airport. Tech. rep., Unique (Flughafen Zürich AG)., Zurich, Switzerland.

[2] Hamilton Sundstrand Technical Information APS3200. https://hsapps.utc.com/powersystems/ products/aps3200pds.htm. [Accessed: 2016-05-04].

[3] Stohlgren, L. M., and Werner, L. D., 1986. “The GTCP36-300, a Gas Turbine Auxiliary Power Unit for Advanced

GTP-17-1390 / Siebel

(C2017 by ASME. This manuscript version is made available under the CC-BY 4.0 license

http://creativecommons.org/licenses/by/4.0/

The original publication is available at $\mathrm{http}: / / \mathrm{dx}$.doi.org/10.1115/1.4038159 
Technology Transport Aircraft”. In Volume 2: Aircraft Engine, Marine, Microturbines and Small Turbomachinery, ASME International.

[4] Kinsey, J., et al., 2012. "Determination of the emissions from an aircraft auxiliary power unit (APU) during the Alternative Aviation Fuel Experiment (AAFEX)". Journal of the Air \& Waste Management Association, 62(4), pp. 420-430.

[5] Crayford, A., et al., 2011. SAMPLE III SC.02 - Studying, sAmpling and Measuring of aircraft ParticuLate Emissions III: Specifc Contract 01 (SAMPLE III - SC.01). Tech. rep., European Aviation Safety Agency.

[6] Lobo, P., Christie, S., Khandelwal, B., Blakey, S. G., and Raper, D. W., 2015. "Evaluation of non-volatile particulate matter emission characteristics of an aircraft auxiliary power unit with varying alternative jet fuel blend ratios". Energy \& Fuels, 29(11), pp. 7705-7711.

[7] ICAO, 2011. Airport Air Quality Manual - Doc 9889. Tech. rep., International Civil Aviation Organization.

[8] Tam, C., Pastouchenko, N., Mendoza, J., and Brown, D., 2005. "Combustion Noise of Auxiliary Power Units". In 11th AIAA/CEAS Aeroacoustics Conference, 23-25 May 2005, Monterey, CA. AIAA-2005-2829.

[9] Tam, C., Parrish, S., Xu, J., and Schuster, B., 2013. "Indirect combustion noise of auxiliary power units". Journal of Sound and Vibration, 332, pp. 4004-4020.

[10] Pott-Pollenske, M., Dobrzynski, W., Buchholz, H., and Almoneit, D., 2007. "Characteristics of noise from aircraft ground operations". In 13th AIAA/CEAS Aeroacoustics Conference, 21-23 May 2007, Rome, IT. AIAA-2007-3560.

[11] Knobloch, K., Busse-Gerstengarbe, S., Fischer, A., Bake, F., and Enghardt, L., 2014. "Full-scale tests on APU noise reduction". In ASME Turbo Expo 2014, June 16-20, Düsseldorf, Germany, no. GT2014-26803.

[12] Cerbe, G., 1992. Grundlagen der Gastechnik, 4th ed. No. ISBN: 3-446-17049-9. Carl Hanser Verlag.

[13] Zornek, T., Monz, T., and Aigner, M., 2015. "Performance analysis of the micro gas turbine turbec t100 with a new flox-combustion system for low calorific fuels". Applied Energy, 159, pp. 276-284.

[14] Walsh, P. P., and Fletcher, P., 2004. Gas Turbine Performance, 2. aufl. ed. John Wiley \& Sons, New York.

[15] do Nascimento et al., M. A. R., 2013. "Micro Gas Turbine Engine: A Review". In Progress in Gas Turbine Performance. InTech, jun.

[16] Bundesministerium für Umwelt (BMU), 2002. TA-Luft: Erste Allgemeine Verwaltungsvorschrift zum Bundes-Immissionsschutzgesetz. Tech. rep., Bundesministerium für Umwelt (BMU).

[17] Lefebvre, A. H., and Ballal, D. R., 2010. GAS Turbine Combustion Alternative Fuels and Emissions. CRC Press Taylor \& Francis Group.

[18] Joos, F., 2006. Technische Verbrennung - Verbrennungstechnik, Verbrennungsmodellierung, Emissionen. Springer.

[19] Schäfer, K., Jahn, C., Sturm, P., Lechner, B., and Bacher, M., 2003. "Aircraft emission measurements by remote sensing methodologies at airports". Atmospheric Environment, 37(37), dec, pp. 5261-5271.

Tables

\begin{tabular}{l|l} 
Thermocouple & $\pm 3.75^{\circ} \mathrm{C}$ \\
\hline Pressure sensor & $\pm 1 \%$ \\
\hline $\begin{array}{l}\text { Exhaust gas analyzer } \\
\text { CO, NO, NOx }\end{array}$ & $\pm 2 \mathrm{ppm}$ \\
\hline $\begin{array}{l}\text { Exhaust gas analyzer } \\
\mathrm{O}_{2}\end{array}$ & $\pm 2 \%$
\end{tabular}

Table 1. ACCURACY OF USED MEASURING EQUIPMENT REFERRED TO MEASURED VALUE

\section{List of figure captions}

Fig. 1: EXPERIMENTAL SETUP;

1: Exhaust duct, 2: Exhaust probe, 3: Bleed air pipe,

4: Air inlet, 5: Control cabinet, 6: Flue gas analyzer

Fig. 2: PROCESS FLOW DIAGRAM WITH MEASURED AND CALCULATED PROPERTIES II, III

Fig. 3: SETUP OF EXHAUST GAS PROPERTY MEASUREMENT; Exhaust gas probe $=\mathrm{a}, p_{\text {tot }}=1, p_{\text {stat }}=2, T_{\text {ex }}=\mathrm{I}$,

Fig. 4: POSITION OF MICROPHONES

GTP-17-1390 / Siebel

(C2017 by ASME. This manuscript version is made available under the CC-BY 4.0 license

http://creativecommons.org/licenses/by/4.0/

The original publication is available at $\mathrm{http}: / / \mathrm{dx}$.doi.org/10.1115/1.4038159 


\begin{tabular}{c|rrrrr}
$\dot{m}_{b l}$ in $\mathrm{kg} / \mathrm{s}$ & 0 & 0.94 & 1.04 & 1.15 & 1.25 \\
\hline$\dot{m}_{B C V}$ in $\mathrm{kg} / \mathrm{s}$ & 0.4 & 0.27 & 0.17 & 0.08 & 0.01 \\
\hline $\mathrm{BCV}$ in $^{\circ}$ & 0 & 69 & 73 & 81 & 89 \\
\hline VIGV in $^{\circ}$ & 82 & 26 & 26 & 35 & 33
\end{tabular}

Table 2. ESTIMATED $\dot{m}_{B C V}$ WITH BCV AND VIGV POSITION;

$\mathrm{BCV}$ is closed: $0^{\circ}$, all mass flow to exhaust;

BCV is open: $90^{\circ}$, all mass flow to aircraft;

VIGV is closed: $82^{\circ}$, VIGV is open for $<40^{\circ}$

\begin{tabular}{c|rrrrr}
$P_{e l}$ in $\mathrm{kW}$ & 4 & 24 & 48 & 73 & 83 \\
\hline$\dot{m}_{b l}$ in $\mathrm{kg} / \mathrm{s}$ & 0 & 0.94 & 1.04 & 1.15 & 1.25 \\
\hline$P_{b l}$ in $\mathrm{kW}$ & 0 & 194 & 216 & 232 & 249 \\
\hline$P_{c p}$ in $\mathrm{kW}$ & - & 240 & 240 & 234 & 252
\end{tabular}

Table 3. ADJUSTED ELECTRIC LOAD AND BLEED AIR MASS FLOW WITH RELATED BLEED AIR AND COMPRESSOR POWER

\begin{tabular}{|c|r|r|r|r|}
\hline$P_{b l}$ in $\mathrm{kW}$ & $P_{e l}$ in $\mathrm{kW}$ & $\mathrm{CO}$ in $\mathrm{ppm}$ & EI of CO & $\lambda_{g l}$ \\
\hline \hline \multirow{2}{*}{0} & 5.4 & 148 & 10.2 & 6.5 \\
\cline { 2 - 4 } & 99 & 135 & 7.4 & 5.1 \\
\hline \multirow{2}{*}{194} & 4 & 87 & 3.8 & 4.3 \\
\cline { 2 - 4 } & 82 & 61 & 2.3 & 3.7 \\
\hline \multirow{2}{*}{249} & 4 & 99 & 4.6 & 5.2 \\
\cline { 2 - 4 } & 82 & 69 & 2.7 & 4.4 \\
\hline
\end{tabular}

Table 4. $\lambda_{g l}$ FOR DIFFERENT LOAD POINTS WITH CORRESPONDING CO EMISSION VALUES

Fig. 5: MEASURED AND CALCULATED MASS FLOWS

Fig. 6: INFLUENCE OF $P_{b l}$ ON $P_{t h}$ FOR CONSTANT $P_{e l}$

Fig. 7: INFLUENCE OF $P_{e l}$ ON $P_{t h}$ FOR CONSTANT $P_{b l}$

Fig. 8: INFLUENCE OF $P_{o v}$ ON $\eta_{o v}$ AND $\eta_{e l}$

Fig. 9: INFLUENCE OF OVERALL POWER OUTPUT ON $T_{e x}$

Fig. 10: IMPACT OF BLEED AIR POWER OUTPUT ON $T_{b l}$ AND $p_{b l}$ FOR CONSTANT $P_{e l}=73 \mathrm{~kW}$

Fig. 11: INFLUENCE OF $P_{o v}$ ON CO EMISSIONS FOR DIFFERENT BLEED AIR AND ELECTRIC LOADS

Fig. 12: INFLUENCE OF $P_{u t}$ ON NOx EMISSIONS FOR DIFFERENT BLEED AIR AND ELECTRIC LOADS

Fig. 13: SPECTRA OF ALL MICROPHONES FOR OPERATING POINT WITHOUT (UPPER) AND WITH BLEED AIR (LOWER PLOT)

Fig. 14: SPECTRA OF UNDISTURBED MICROPHONE FOR LOAD VARIATIONS. UPPER PLOT: VARIED BLEED AIR (MAXIMUM ELECTRIC POWER), LOWER PLOT: VARIED ELECTRIC LOAD (MAXIMUM BLEED AIR) 